\title{
Caracterización de neumonías y tratamiento quirúrgico en pacientes pediátricos
}

\section{Characterization of pneumonias and surgical treatment in pediatric patients}

Rosario H. Zambrano-Bonilla ${ }^{\text {I }}$

Universidad de Guayaquil

Guayaquil, Ecuador

\author{
Alfredo X. Dávila-Zambrano II \\ Universidad de Guayaquil \\ Guayaquil, Ecuador \\ Carlos A. Vizueta-Chávez III \\ Universidad de Guayaquil \\ Clínica Kennedy \\ Guayaquil, Ecuador \\ drcvizuetach@hotmail.com; carlos.vizuetac@ug.edu.ec
}

Jorge E. Balon-Benavides IV

Universidad de Guayaquil

Guayaquil, Ecuador

Recibido: 30 de enero de 2017 * Corregido: 20 de febrero de $2017 *$ Aceptado: 20 junio de 2017

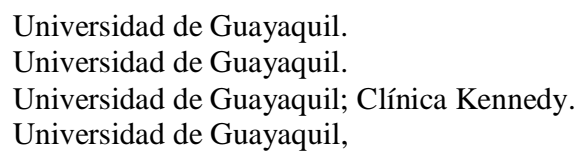




\section{Resumen}

La neumología en niños es una de las patologías más frecuentes en pacientes pediátricos, con una incidencia muy elevada en los niños menores de 5 años y con una prevalencia mayor en niños de países en vías de desarrollo. La caracterización epidemiológica es importante para el correcto manejo de esta patología. Actualmente no se contaba con un trabajo similar en el Hospital "Francisco de Icaza Bustamante" y esta información es fundamental para el desarrollo de programas de contingencia, prevención, promoción de salud y diagnostico precoz. Objetivo: Establecer las características epidemiológicas y demográficas de los casos de neumonías atendidas en pacientes pediátricos con cuadros neumológicos atendidos en esta de asistencia en el periodo 2010. Metodología: Se realizó un estudio transversal en el que se incluyeron 2465 pacientes pediátricos atendidos por neumología en el hospital en el que se incluyeron entre el 1 de enero al 31 de diciembre del 2010. Análisis Estadístico: Para las variables cuantitativas promedio y desviación estándar, para las variables cuantitativas frecuencias simples y porcentajes. Resultados: Marzo, abril y mayo fueron los meses con mayor incidencia de casos $(\mathrm{n}=983)$. El promedio mensual de casos es de 205,4 \pm 84,62 la proporción de hombres y mujeres fue similar (45 \% y 55\%). El 92\% de los afectados pertenecieron al grupo de 0 a 4 años con una edad promedio de 1.3 años. El $89 \%$ procedía de la provincia del Guayas. El 9\% de los cuadros fueron producidos por virus, parásitos, bacterias o químicas, y en el $91 \%$ no se conoció el agente. El 94\% tuvo una estadía hospitalaria de 1 a 14 días de un promedio de $6,5 \pm 5,3$ días.

Palabras clave: Neumología, pediátrica, patologías. 


\section{Abstract}

Pneumology in children is one of the most frequent pathologies in pediatric patients, with a very high incidence in children under 5 years of age and with a higher prevalence in children from developing countries. The epidemiological characterization is important for the correct management of this pathology. Currently there is no similar work at the Hospital "Francisco de Icaza Bustamante" and this information is essential for the development of contingency programs, prevention, health promotion and early diagnosis. Objective: To establish the epidemiological and demographic characteristics of the cases of pneumonia seen in pediatric patients with pneumological symptoms attended in this period in 2010. Methodology: A cross-sectional study was carried out in which 2465 pediatric patients attended by pulmonology were included in the study. hospital in which were included between January 1 to December 31, 2010. Statistical Analysis: For the average quantitative variables and standard deviation, for the quantitative variables simple frequencies and percentages. Results: March, April and May were the months with the highest incidence of cases (n $=983$ ). The monthly average of cases is $205.4 \pm 84.62$, the proportion of men and women was similar (45\% and 55\%). $92 \%$ of those affected belonged to the group of 0 to 4 years with an average age of 1.3 years. $89 \%$ came from the province of Guayas. 9\% of the tables were produced by viruses, parasites, bacteria or chemicals, and in $91 \%$ the agent was not known. $94 \%$ had a hospital stay of 1 to 14 days averaging $6.5 \pm 5.3$ days.

Key words: Pulmonology, pediatric, pathologies. 


\section{Introducción.}

La neumonía es una de la patología de mayor frecuencia en niños. Su incidencia es más elevada en niños menores de 5 años de edad (36 a 40 episodios / 1000 niños/ año) y disminuye hasta 11 a 16 episodios / 1000 niños / años de los niños 5 a 14 años de edad ${ }^{1-3}$.

A pesar de esta elevadas morbilidad, la mortalidad por neumonía en los niños previamente sanos, en los países desarrollados, es muy baja, a diferencia de los adultos en la moralidad para los pacientes hospitalizados es del 14\%. Además de ser más frecuentes las neumonías en los niños menores de 5 años de edad también suelen revertir una mayor gravedad ${ }^{4}$.

Los niños con neumonía menores de 5 años, un 55\% fueron tratados en el hospital, mientras que de los mayores de 5 años ingresaron son un $11 \%{ }^{5,6}$.

Los cuadros neumónicos son un problema en países en desarrollo. Ecuador a sufrido un aumento de la incidencia de esta patología entre la población pediátrica y actualmente se han incrementado los caso.

Se consideró necesario que el hospital Francisco de Icaza Bustamante siendo una institución de salud de gran importancia para la ciudad de Guayaquil y la región sur y centro el Ecuador, debería constar con información actualizada que permita conocer las características de este cuadro patológico sobre la morbilidad y mortalidad infantil.

Con este objetivo se realizó un estudio transversal que incluyo de manera no aleatoria y por conveniencia 2465 casos de neumonía atendidos en el periodo 1 de enero a 31 de diciembre del 2010 que correspondieron a toda la población de cumplió con los criterios de selección. 


\section{Materiales y métodos.}

La información que se expone a continuación sea estructurada de forma tal que provea bases conceptuales y referenciales respecto a las características particulares de las neumonías en pacientes pediátricos, aplicables a nuestro medio. El trabajo también señala los lineamientos metodológicos del estudio y describe las características de la población afectada, los antecedentes importante al momento de estudiarlas su evolución, su diagnóstico y tratamiento.

\section{Población}

El universo estuvo constituido por pacientes pediátricos con diagnóstico de neumonía que fueron atendidos en la institución. La población de estudio debió cumplir lo siguiente criterios de selección:

\section{Criterios de Inclusión}

- Ingreso en el periodo de estudio

- Acceso al expediente clínico

\section{Criterios de Exclusión}

- Diagnostico en proceso

- Diagnóstico no concluyente

\section{Muestra}

Se incorporaron todos los pacientes incluidos como población de estudio $(n=2465)$ 


\section{Diseño de investigación}

Observacional- descriptivo

\section{Procedimiento}

Se procedió a la búsqueda en el sistema informático de documentación a la identificación de los casos según la clasificación CIE 10: J09-J10,J12,J13,J14,J15,J16,J17,J18.

Luego se precedió a solicitar la información en un formato de Excel y se procedió recopilar la información en el formulario creado para el efecto.

\section{Consideraciones Éticas}

El procedimiento no infringió ninguno de los derechos fundamentales de los pacientes ya que se limita a la descripción de las características de una población, guardando la confidencialidad e identidad de los caso.

\section{Análisis estadístico}

Par la descripción de las variables cuantitativas se utilizó promedios, desviación estándar, error estándar. Para la descripción de las variables cualitativas, se emplearon frecuencias simples y porcentajes. 


\section{Resultados.}

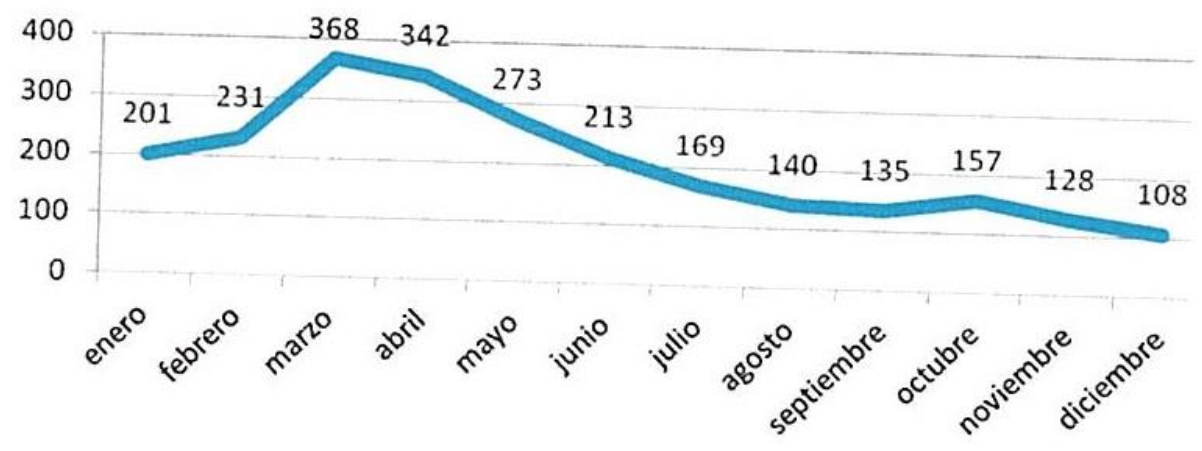

\section{Grafico $N^{\circ}$ 1.- Incidencia mensual de cuadros de Neumonía, periodo 2010}

El promedio de ingresos mensuales por cuadros de neumonía en el Hospital FIB; fue de aproximadamente 205,4 $\pm 84,62$ pacientes. Los meses con mayor incidencia en el periodo de estudio fueron marzo, abril y mayo que corresponde a los meses de la temporada invernal.

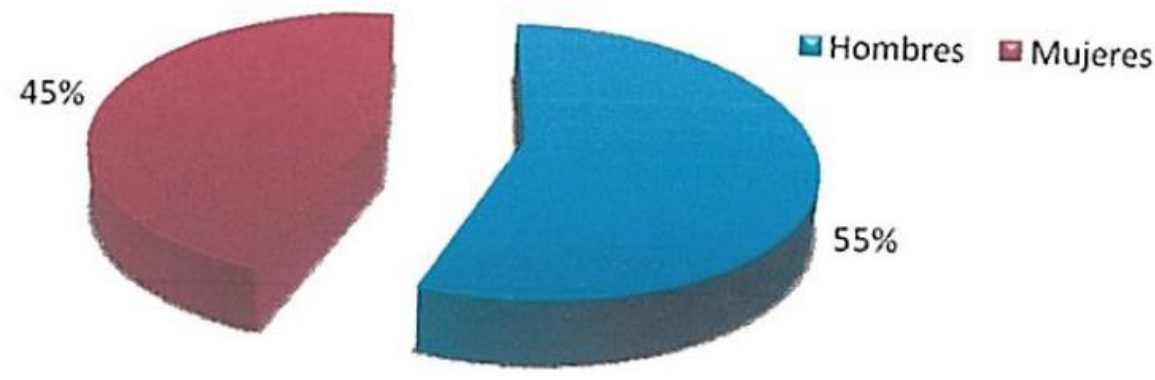

Grafico $N^{\circ}$ 2.- Distribución de los casos de neumonía según sexo

La proporción de hombres y mujeres afectados por un cuadro de neumonía en el periodo de estudio fue muy similar (45\% vs $55 \%)$. 


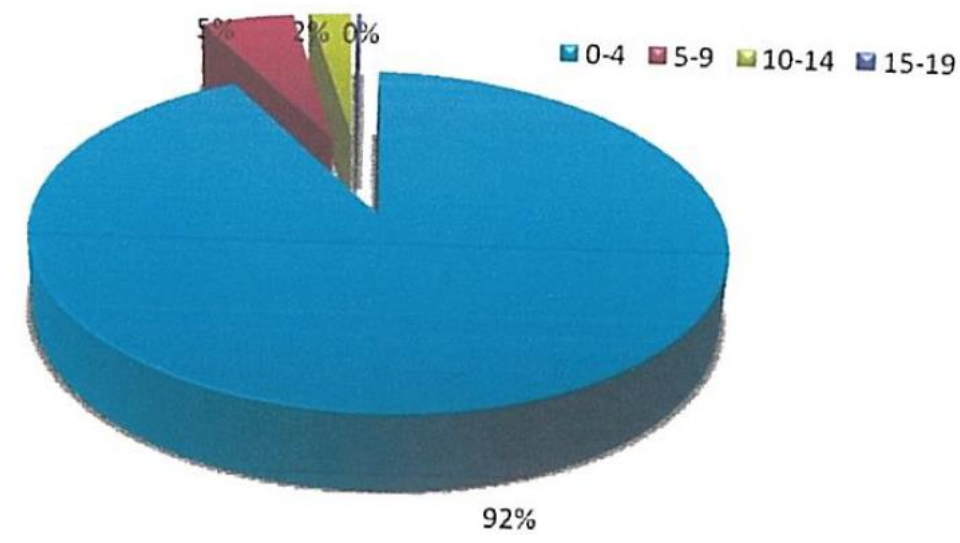

\section{Grafico $N^{\circ}$ 3.- Distribución de los casos de neumonía según grupos de edad}

El grupo de edad que fue mayormente afectado por un cuadro de neumonía fue el de 0 a 4 años $(n=2269)$.

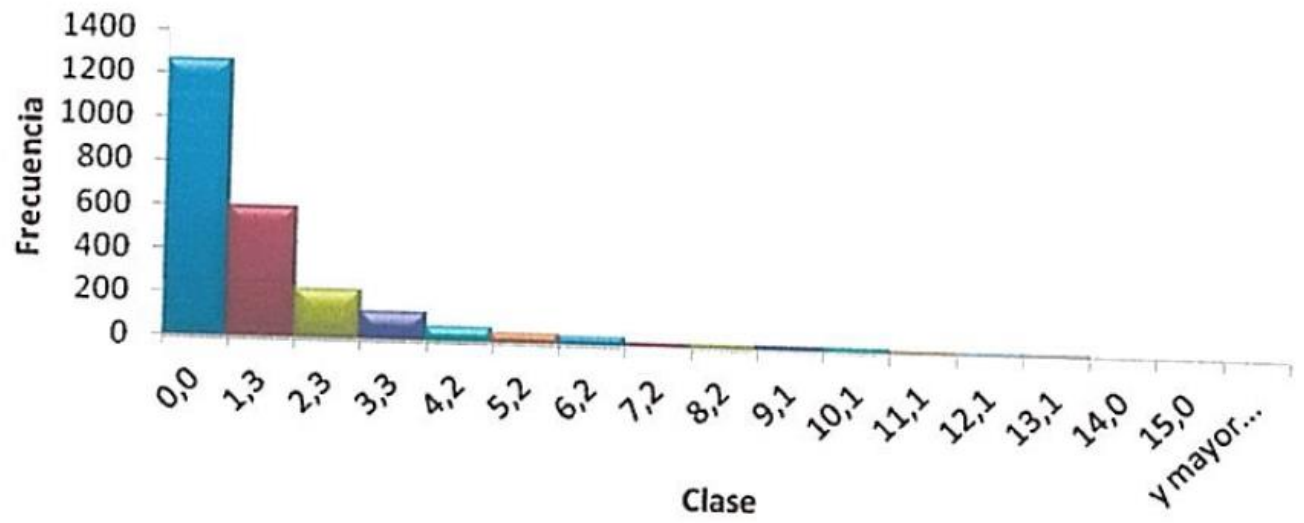

\section{Grafico $N^{\circ}$ 4.- Histograma de la edad de los pacientes con neumonía}

La edad promedio de los pacientes que desarrollan un cuadro de neumonía y que fueron atendidos en la institución fue de 1,3 años, con una distribución no normal de la curva hacia la izquierda. 


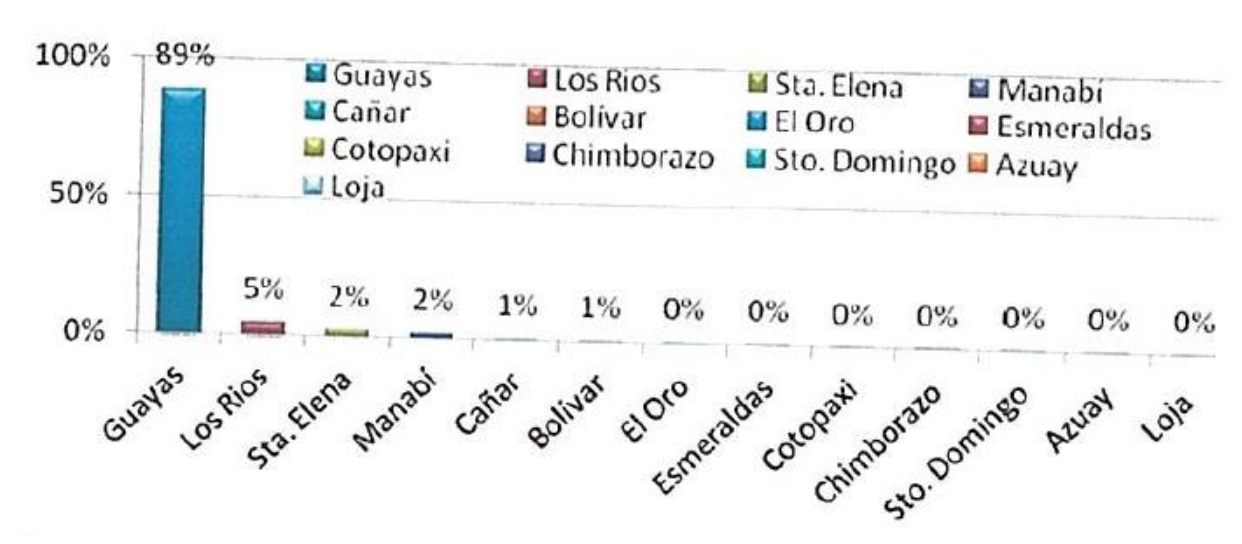

\section{Grafico $N^{\circ}$ 5.- Distribución de los casos de neumonía según procedencia}

La mayor parte de los casos de neumonía de niños procedió de la provincia del Guayas (n=2188). La segunda provincia que aporto con mas pacientes fue los Ríos $(n=113)$. El resto de provincias aporto con el $6 \%$ de los casos.

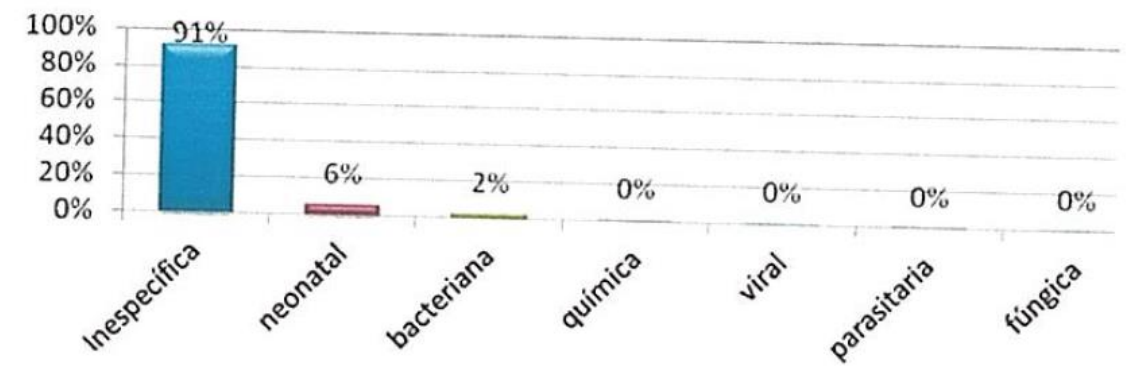

\section{Grafico $N^{\circ}$ 6.- Distribución de casos de neumonía según Etiología}

Frecuentemente los casos de neumonía no tuvieron etiología conocida $(n=2251)$ o fueron de origen neonatal $(n=137)$. El restante $3 \%$ de casos se produjo por virus, bacterias, parásitos, fúngica, química. 


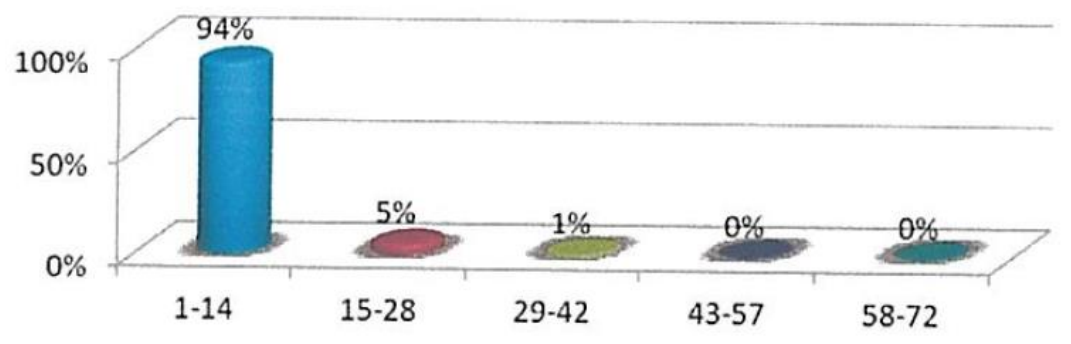

\section{Grafico $N^{\circ}$ 7.- Distribución de los caso de neumonía según estancia hospitalaria}

La estancia hospitalaria más frecuentes fue de 1 a 14 días $(n=2310)$ y de 15 a 28 días $(n=133)$

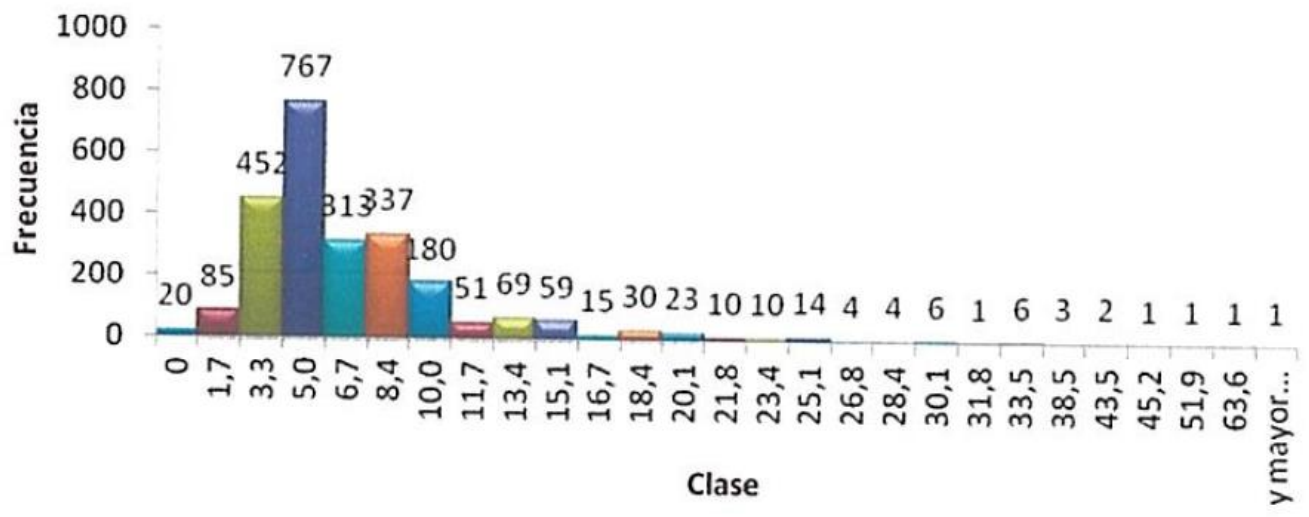

\section{Grafico $N^{\circ}$ 8.- Histograma de la estancia hospitalaria de los pacientes con neumonía}

El tiempo promedio de estancia hospitalaria entre pacientes con diagnóstico de neumonía fue

6,5 $\pm 5,3$ días común deviación no normal de curva hacia la izquierda. 


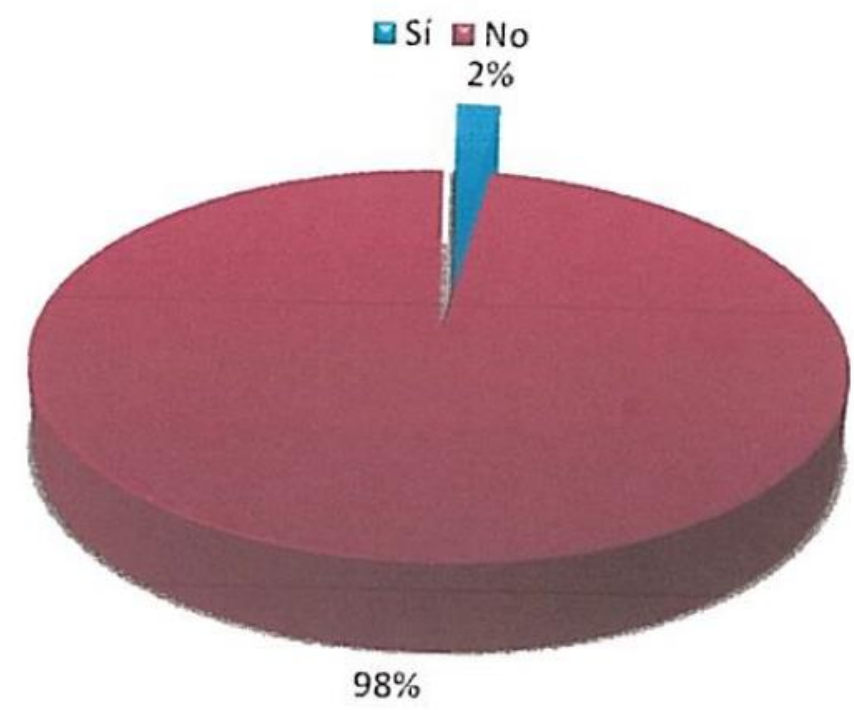

Grafico $N^{\circ}$ 9.- Distribución de los casos de neumonía según necesidad de cuidados intensivos

Un total de 53 pacientes pediátricos con u cuadro de neumonía requerido una atención en cuidados intensivos 


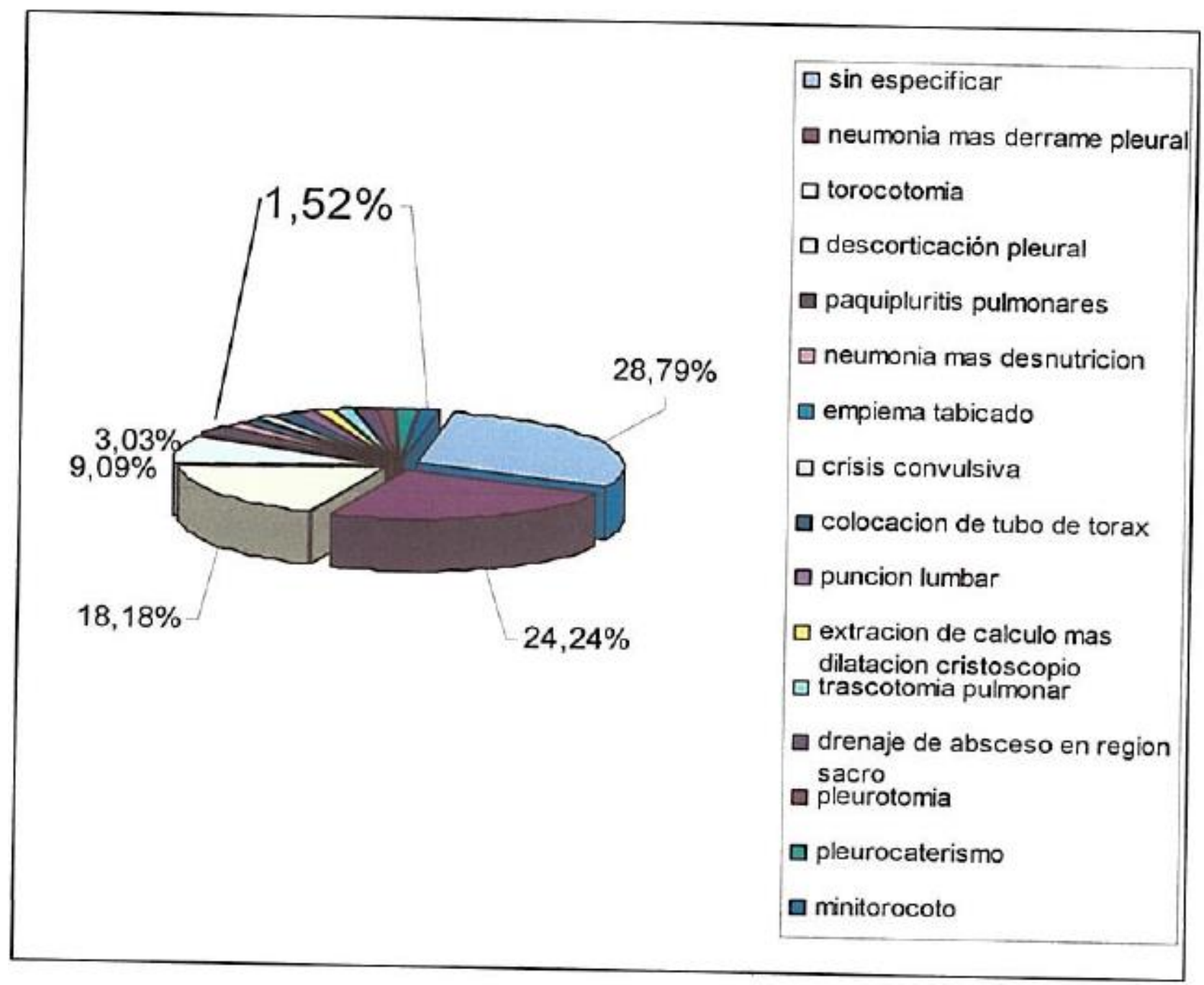

Grafico $N^{\circ}$ 10.- Distribución de los casos de neumonía según tipo de cirugía

Un total de 66 pacientes pediátricos con un cuadro de neumonía necesitaron de una intervención quirúrgica. 


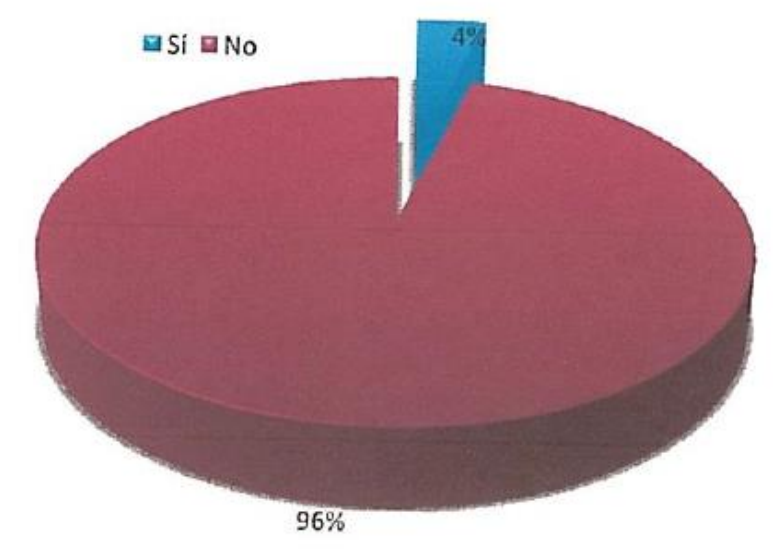

\section{Grafico $N^{\circ}$ 11.- Mortalidad de los caso de Neumología}

La mortalidad de los pacientes pediátricos provocado por un cuadro de neumonía fue el $4 \%$.

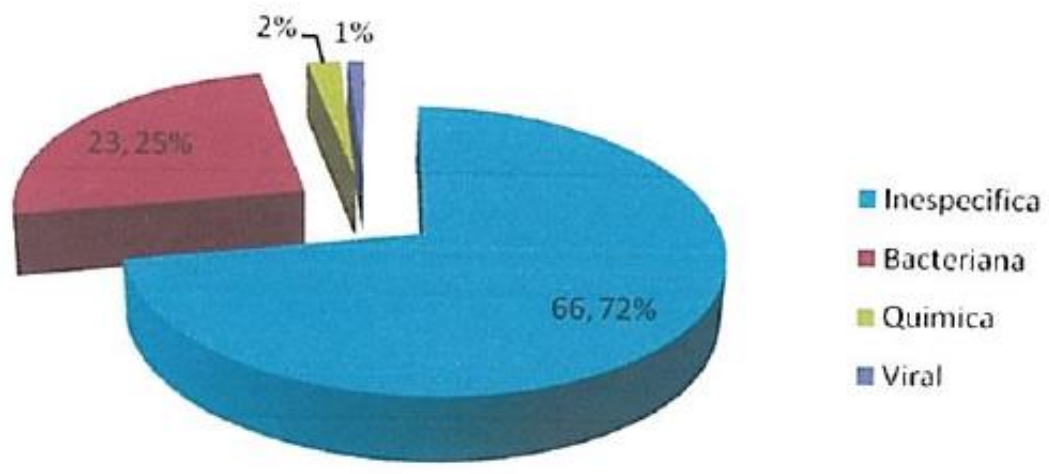

\section{Grafico $N^{\circ}$ 12.- Etiología de la neumonía entre pacientes que fallecieron}

Entre los pacientes pediátricos que murieron, 66 pacientes tuvieron una neumonía de etiología no especificada y 23 de origen bacteria y 2 de origen químico y 1 de origen viral. 


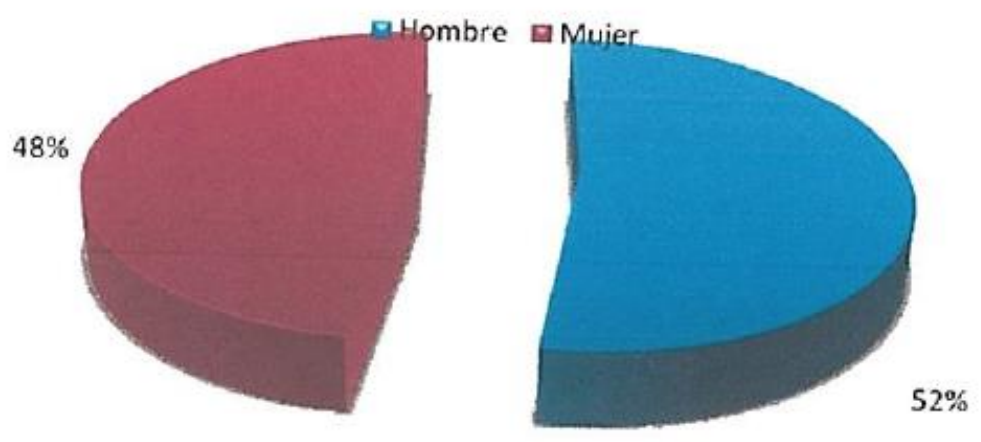

\section{Grafico $N^{\circ}$ 13.- Sexo de los pacientes con neumología}

La proporción de pacientes de sexo masculino y femenino, fue similar entre los niños que murieron por un cuadro de neumonía (52\% vs 48\%)

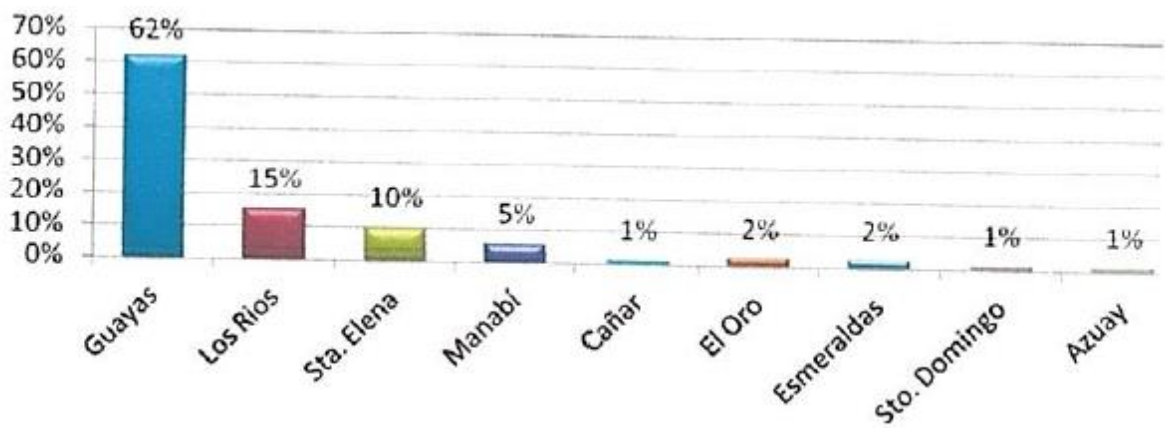

Grafico $N^{\circ}$ 14.- Fallecidos por provincias

\section{Discusión.}

La estación del año y la localización geográfica son factores que predicen la etiología. En los meses de invierno aumenta la frecuencia de neumonías, tanto adquirida en la comunidad como en instituciones. En esto tiene una correcta correspondiente con el estudio efectuado, donde se puede ver que la mayor incidencia de cuadros neumónicos se produjo precisamente en época de invierno. 
Los resultados obtenidos van de acuerdo a la información obtenida en la literatura, donde se reporta que los menores de 5 años es el grupo de edad más afectado de manera especial los menores de 1 año. El Género con mayor incidencia se ha señalado que es el masculino sin embargo en la investigación se pudo observar que hubo una afectación similar.

En varios estudios en otros países de Latinoamérica el 93\% de los casos de neumonías no tienen diagnóstico etiológico. En el presente trabajo el $75 \%$ no fue descrito con agente causal y esto es preocupante ya que el conocimiento de la etiología es importante para aplicar en forma oportuna el tratamiento de neumonía. Se ha señalado que en aproximadamente un tercio de los pacientes pediátricos es difícil encontrar la etiología microbiana más específica por ejemplo, cuando no se dispone de esputo para el examen más aun considerando que los niños no expectoran ${ }^{7}$.

En la literatura se ha descrito que los virus respiratorios son los agentes causales más frecuentes de la neumonía durante los primeros años de vida sin embargo en el estudio hay dos diferencias fundamentales: la causa infecciosa viral no fue la principalmente identificada entre las infecciosas, fue la bacteriana, y segundo, la forma clínica principal en este grupo fue la neumonía neonatal ${ }^{8}$.

\section{Conclusiones.}

Los resultados que se acaban de presentar llevan a concluir que la mayor parte de las neumonías tratadas en el hospital "Francisco de Icaza Bustamante" son atendidas en la época invernal. Generalmente son de etiología no identificada, y el grupo más afectado son los neonatos. Entre las neumonías provocadas por agentes infeccionas las de tipo bacteriano son las pudieron confirmarse. La población afectada es similar en relación al sexo, proceden de la ciudad de 
Guayaquil y generalmente tienen menos de 5 años. La mayoría tiene una estancia hospitalaria menos de 1 semana.

Un reducido porcentaje requiere de cuidados intensivos y cirugía como parte del tratamiento. La mortalidad es muy baja.

El $50 \%$ de los pacientes requieren cuidados intensivos y un limitado grupo de 66 pacientes (3\%) requirió intervención quirúrgica.

Los pacientes que mueren generalmente desarrollan una meningitis de etiología inespecífica, son de sexo masculino con una edad de 0 a 4 años, procedentes del Guayas, de lo cual se deduce que en este grupo de edades están los microorganismos patógenos más agresivos, que son etiología inespecífica, los cuales no han podido ser identificados, lo que limitó el accionar terapéutico asumido lo que conlleva al paciente a la muerte.

El $90 \%$ de la meningitis provienen de unas infecciones previas de las vías respiratorias inferiores o superiores, los microorganismos que provocan las meningitis pueden ser recuperados a partir de Líquido Céfalo Raquídeo.

\section{Bibliografía.}

1. Gómez Carcassés LM, Pérez Hernández L, Pujol Enseñat Y, Piña Loyola CN. Caracterización de pacientes con neumonía por Acinetobacter baumannii asociada a la ventilación mecánica en las Unidades de Cuidados Progresivos. MediSur. 2016 Ene; 14(4): p. 389-403.

2. Allúe X, Lorente M. Oxigenoterapia. In López-Herce J, Calvo C, Lorente M. Manual de Cuidados Intensivos Pediátricos. Madrid: Publimed; 2001. p. 584-590.

3. Díaz Mayo J, Rivero Martínez H, Pupo San Juan Y, Carballo Navarro A. Caracterización de pacientes con neumonía asociada a ventilación artificial mecánica. Revista Cubana de Medicina 
Intensiva y Emergencia. $2013 \mathrm{Jul} ; 13(3)$.

4. Organización Mundial de la Salud. Informe sobre la Salud en el Mundo 2003 Ginebra: OMS; 2003.

5. Saldías P F, Mardónez U JM, Marchesse R M, Viviani G P, Farías G G. Neumonía adquirida en la comunidad en el adulto hospitalizado. Cuadro clínico y factores pronósticos. Revista médica de Chile. 2002 Dic; 130(12).

6. Garibaldi R. Epidemiology of community-acquired respiratory tract infections in adults: incidence, etiology and impact. Am J Med. 1985; 78(1): p. 32-37.

7. Barrios López M. Características epidemiológicas, clínicas y microbiológicas de las infecciones por Staphylococcus aureus adquirido en la comunidad en pediatría. Memoria para optar el grado de doctor. Madrid: Universidad Complutense de Madrid, Departamento de Pediatría; 2012.

8. Somogyi T, Alfaro W, Herrera ML, Herrera JF. Infecciones del tracto respiratorio: etiología bacteriana y viral en una población pediátrica. Revista Médica del Hospital Nacional de Niños Dr. Carlos Sáenz Herrera. 1998; 33(1-2). 